\title{
PARTICIPACIÓN POLÍTICA CIUDADANA EN MICHOACÁN
}

\author{
Citizen political participation in Michoacán
}

\section{Yurisha Andrade Morales}

Universidad Michoacana de San Nicolás de Hidalgo, Morelia, Michoacán, Mexico.

E-mail: yurishaa@hotmail.com

Trabalho enviado em 27 de fevereiro de 2018 e aceito em 15 de janeiro de 2022

\section{(c) (i)}

This work is licensed under a Creative Commons Attribution 4.0 International License. 


\section{RESUMEN}

La democracia es una forma de organización social que atribuye la titularidad del poder al conjunto de la sociedad. Sin embargo, para que el pueblo ejerza verdaderamente este poder, es ineludible que los ciudadanos tomen parte en las cuestiones públicas. Por tanto, la participación de los ciudadanos es sustancial para que el gobierno se convierta verdaderamente en el gobierno del pueblo, ya que modera y controla el poder de los políticos y porque la sociedad se hace escuchar en la toma de decisiones. Existen múltiples formas de tomar parte en los asuntos públicos, la participación política, donde se encuentra el sufragio, es sólo una de ellas, pero también existe la participación social, comunitaria y ciudadana.]

Palabras clave: Participación política, participación ciudadana, ciudadanía, cultura política, instituciones.

\section{ABSTRACT}

Democracy is a form of social organization that attributes the ownership of power to the whole of society. However, for the people to truly exercise this power, it is unavoidable that citizens take part in public issues. Therefore, the participation of citizens is substantial for the government to truly become the government of the people, since it moderates and controls the power of politicians and because society makes itself heard in decision-making. There are multiple ways of taking part in public affairs, political participation, where suffrage is found, it is just one of them, but there is also social, community and citizen participation.

Keywords: Political participation, citizen participation, citizenship, political culture, institutions.

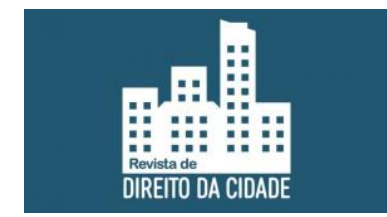

Rev. de Direito da Cidade, Rio de Janeiro, Vol. 14, N.01., 2022, p. 411-429.

Yurisha Andrade Morales

DOI:___ ISSN 2317-7721 


\section{INTRODUCCIÓN}

Para lograr una verdadera democracia es fundamental la participación de la ciudadanía en los asuntos públicos, lo que permitirá que sus opiniones sean escuchadas e incluidas por parte de quienes ejercen el poder y de esta manera satisfacer las principales necesidades del ser humano que se encuentra inmerso en una sociedad.

La democracia requiere que el poder se ejerza de la mano de la sociedad, que sea incluyente en la toma de decisiones que sean del interés público.

Las diversas reformas constitucionales y legales han dado pauta a la apertura de la participación política, sobre todo a partir de los años setenta, lo que permitió asentar las bases para que se lograran elecciones más competitivas y equitativas.

\section{CIUDADANÍA, CIUDADANÍA INTEGRAL Y CIUDADANÍA POLÍTICA}

Inicio intentando definir ¿qué entendemos por ciudadanía? Marshall la concibe como “... un estatus que se otorga a los que son miembros de pleno derecho en una comunidad.Todos los que poseen ese estatus son iguales en lo que se refiere a los derechos y deberes que implica" (MARSHALL, 2009). Marshall también propuso una división tripartita de los derechos: civiles, políticos y ociales:

"El componente civil está constituido de los derechos necesarios para la libertad individual, la libertad de la persona, de pensamiento, palabra y creencia, el derecho a establecer contratos de propiedad sobre la tierra y el derecho a la justicia...Por el componente político me refiero al derecho de participar en el ejercicio del poder político, como miembro de un cuerpo investido de autoridad política o como un elector ... Por el componente social quiero decir a todo lo que va del derecho a un mínimo de bienestar y seguridad económico hasta el derecho de compartir plenamente la herencia social y a vivir la vida de un ser civilizado de acuerdo a los parámetros prevalentes de la sociedad" (MARSHALL, 2009).

Guillermo O’Donnell señala que en un Estado democrático se debe garantizar el ejercicio de una "ciudadanía integral" entendida esta como "la ciudadanía que accede de manera armoniosa a sus

DOI: | ISSN 2317-7721 
derechos cívicos, sociales económicos y culturales" (PNUD, 2004). Es entonces que la ciudadanía integral se logra cuando las personas que la conforman se asumen como titulares de derechos, prerrogativas y potestades políticas; asimismo implica que los ciudadanos cuenten con las condiciones necesarias para ejercer sus derechos y asumir sus responsabilidades.

Si profundizamos en el concepto de "ciudadanía política" a quien Michael Mann define como "la capacidad de participar e influir en los procesos de adopción e implementación de decisiones colectivas (mayoritariamente vinculantes), a partir del empleo de recursos legítimos de diversas clases, y donde la naturaleza vinculante de las decisiones, descansa en la coerción y regulaciones estatalmente centralizadas y territorialmente circunscritas" (MANN, 1986).

El concepto ampliado de ciudadanía política que adoptaron en 2010 el Programa de las Naciones Unidas para el Desarrollo (PNUD) y la Organización de los Estados Americanos (OEA) "connota el derecho a participar en el ejercicio del poder político como miembro de un cuerpo investido de autoridad política o como elector de sus miembros" (NOTO, 2014). En el estudio publicado en 2014 por el PNUD denominado "Ciudadanía política: voz y participación ciudadana en América Latina" se clasifican los recursos ofrecidos a los ciudadanos en términos de su acción política según el grado de institucionalización de los mismos y si se trata de participación en procesos democráticos o de participación directa (NOTO, 2014):

\begin{tabular}{|l|l|l|}
\hline Institucionalizados & Pemocrático-representativos & Participación directa \\
\hline Baja institucionalización & Militancia en partidos, etc. & $\begin{array}{c}\text { nstancias macro y micro de } \\
\text { participación directa }\end{array}$ \\
\hline No institucionalizados & ráfico de influencias, lobby, \\
etc. & $\begin{array}{c}\text { Protesta callejera, sentadas, } \\
\text { etc. }\end{array}$ \\
\hline
\end{tabular}

DOI: | ISSN 2317-7721 
Como parte de los resultados que muestra este estudio se identificó que América Latina sigue estando en el último lugar en cuanto a los índices de satisfacción de la democracia, siendo este el 37\%, comparado contra Asia que registra el 70\%, Europa el 59\% y África el 49\%. Es decir, los latinoamericanos son los más insatisfechos con su democracia, tienen altas expectativas y crecientes grados de empoderamiento y opiniones cada vez más críticas.

Por su parte, en el Latinobarómetro 1995-2015, instrumento de medición basado en 20000 ecuestas cara a cara en 18 países, se puede identificar que de los países que componen América Latina, sólo tres registran más de la mitad de su población satisfecha con su democracia: Uruguay, Argentina y República Dominicana. México se ubica en el último lugar con 19\%. Cabe mencionar que estos indicios se asocian a persistentes niveles de desconfianza en las instituciones de la democracia junto con una alta percepción de injusticia social.

Se identifica también que los 20 años de mediciones confirman que existe una estrecha relación entre la satisfacción con la democracia y el desempeño económico, pues el nivel de satisfacción se ve afectado con las crisis económicas, produciéndose una disminución para la crisis asiática (1999-2001), un aumento durante el quinquenio virtuoso (2002-2007) y las políticas económicas contra cíclicas ante la crisis (2008-2009), para volver a bajar al desacelerarse la economía china y la llegada de la crisis europea (2010).

Se consultó a los encuestados ¿qué es más efectivo para influir y cambiar las cosas?, siendo una de las alternativas de respuesta "Votar para elegir a los que defienden mi posición". Se observó que cuatro países se ubican en el intervalo del 70 al $80 \%$ de respuestas positivas a esta afirmación: Venezuela, Uruguay, República Dominicana y Nicaragua; cinco países se ubicaron en el intervalo de 60 y $69 \%$ : El Salvador, Argentina, Costa Rica, Panamá y Brasil; y nueve países se ubicaron en el rango de 51 a 59\%: Paraguay, México, Bolivia, Colombia, Chile, Guatemala, Honduras, Ecuador y Perú.

En la encuesta levantada para el Latinobarómetro 2015 también se les preguntó si estaban de acuerdo con la afirmación "La democracia es preferible a cualquier otra forma de gobierno" el promedio de la región es que el $56 \%$ está de acuerdo, sin embargo, oscila entre el $33 \%$ en el caso de Guatemala, hasta el $84 \%$ que se registró en Venezuela. México se ubicó en el $48 \%$, es decir menos de la mitad de los encuestados.

En el estudio elaborado por el PNUD, que mencioné anteriormente, se analiza la participación electoral en la región para el periodo comprendido de 2000 a 2012 que en promedio es del 69.5\%. Se observa que de los 17 países que se estudian, ocho registran una participación electoral estable, entre

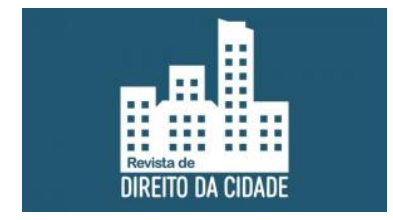

Rev. de Direito da Cidade, Rio de Janeiro, Vol. 14, N.01., 2022, p. 411-429.

Yurisha Andrade Morales

DOI:__ ISSN 2317-7721 
ellos México, acompañado de Uruguay, Argentina, Brasil, República Dominicana, Costa Rica, Paraguay y Colombia. Por su parte, seis países muestran una tendencia creciente: Ecuador, Perú, Bolivia, Venezuela, El Salvador y Guatemala y sólo tres países: Panamá, Chile y Honduras tienen una tendencia decreciente.

En el Latinobarómetro también se encuentran datos sobre la percepción que tienen los ciudadanos sobre la limpieza de las elecciones en su país, en Latinoamérica el $47 \%$ de los ciudadanos considera que las elecciones son limpias, siendo Uruguay el país que registra el índice mayor con $82 \%$ y México el índice más bajo con $26 \%$. Este mismo estudio señala que en la región sólo el $23 \%$ de los encuestados se sienten políticamente representados por sus parlamentos o congresos, siendo nuevamente Uruguay quien registra el índice más alto $45 \%$ y Perú registra sólo el $8 \%$. México se ubica en la décimo quinta posición con el $17 \%$.

Los cimientos de una democracia y de una ciudadanía integral radican en la participación ciudadana en la vida social, es decir, en la solución conjunta y solidaria de los problemas de la colectividad. Para ello, es necesario el impulso de la cohesión social que se manifiesta en la participación en organizaciones o redes sociales, en las normas de confianza interpersonal y en la reciprocidad. Cuando existen dichos factores, la acción colectiva se vuelve más sencilla y los ciudadanos recurren con mayor frecuencia a la resolución de problemas comunitarios con sus pares.

En México, hay una vida comunitaria que necesita fortalecerse y los ciudadanos necesitan desplegar mejor su capacidad para organizarse y resolver los problemas públicos. De acuerdo con los resultados del Informe País sobre la calidad de la ciudadanía en México casi $46 \%$ de los encuestados reportó que nunca ha tenido alguna membresía en alguna organización, cifra que revela la delicada condición del tejido social que tenemos y, en consecuencia, la endeble base sobre la que se erige nuestra democracia.

\section{CIUDADANÍA Y PARTICIPACIÓN CIUDADANA EN MÉXICO}

El Informe País sobre la calidad de la ciudadanía en México es un estudio que se realizó entre 2013 y 2014 que tiene como propósito mostrar la calidad de la ciudadanía en México a través de 6 dimensiones: Ciudadanía, estado de derecho y acceso a la justicia; Vida política y calidad de la ciudadanía; Sociedad civil y ciudadanía (participación no electoral); Vida comunitaria y ciudadanía; Valores y calidad de la ciudadanía; y Ciudadanía y redes personales y organizacionales.

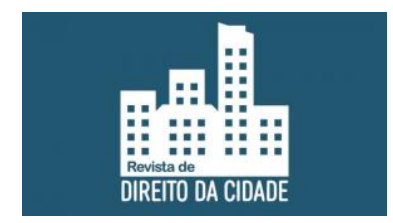

Rev. de Direito da Cidade, Rio de Janeiro, Vol. 14, N.01., 2022, p. 411-429.

Yurisha Andrade Morales

DOI:__ ISSN 2317-7721 
Se identificó que existían múltiples encuestas y estudios que tenían como propósito medir distintos factores que atañen a la construcción de ciudadanía en nuestro país: El Estudio Nacional Electoral elaborado por el CIDE; la Encuesta Nacional sobre Cultura Política y Prácticas Ciudadanas elaborada por la Secretaría de Gobernación; el Latinobarómeto y diversas encuestas de confianza ciudadana como las elaboradas por el COLMEX-CDD y Consulta Mitofsky. Se planteó la necesidad de diseñar un estudio que contemplara un conjunto de indicadores que nos permitiera identificar de manera precisa la situación actual de la cultura política y la calidad ciudadana de nuestro país, que se posicionara como un referente en esta materia por ser el entonces IFE la autoridad electoral facultada para ello. Ningún estudio de los que mencioné anteriormente tienen una cobertura de aplicación de 11,000 encuestas cara a cara sólo en México; porque hay que decir que el Latinobarómetro aplica 20,000 encuestas, pero distribuidas en 18 países.

A partir de los resultados del Informe País se puede concluir que México atraviesa un complejo proceso de construcción de ciudadanía caracterizado por sus relaciones de desconfianza en el prójimo y en la autoridad, especialmente en las instituciones encargadas de la procuración de justicia; por su desvinculación en redes para acceder a bienes y servicios que vayan más allá de la familia, los vecinos y algunas asociaciones religiosas y por su desencanto por los resultados que ha tenido la democracia en México (Informe País sobre la calidad de la ciudadanía en México, 2015). Por ende, el principal problema público a atender es la baja calidad de la ciudadanía en nuestro país.

La participación política es una actividad fundamental para la democracia por dos razones: la movilidad política - que los ciudadanos puedan, partiendo desde abajo, ascender a posiciones de gobierno o representación mediante su participación- y la influencia de los ciudadanos sobre los tomadores de decisiones.

El voto es la medida de participación más común en las democracias liberales. En el Informe País se elaboró un modelo logístico para explicar la participación electoral. La variable que mayor impacto tiene sobre el voto es la identidad partidaria, es decir, identificarse con un partido incrementa la probabilidad de votar. De la misma manera, la edad y el género son dos variables que inciden en la tasa de participación electoral.

La incidencia de esas dos variables en la participación electoral la confirman los Estudios Censales de participación ciudadana en las elecciones de 2009, 2012 y 2015 elaborados por la autoridad electoral nacional, con estos estudios se busca identificar el perfil de quienes ejercían su voto así como de quienes

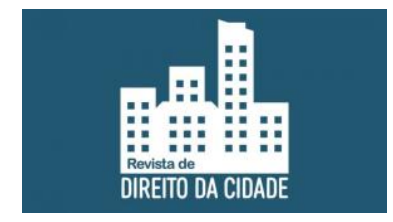

Rev. de Direito da Cidade, Rio de Janeiro, Vol. 14, N.01., 2022, p. 411-429.

Yurisha Andrade Morales

DOI:___ ISSN 2317-7721 
se abstenían, usando las variables de sexo, edad y tipo de sección, identificándose que son las mujeres entre 50 y 69 años de secciones rurales las que registran un mayor índice de participación y a los hombres entre 20 y 39 años, así como de más de 80 años en secciones urbanas o mixtas como el perfil de los ciudadanos que menos participan en las elecciones a través de la emisión del voto. Si se analiza el comportamiento de la participación en las elecciones federales en nuestro país, a través del voto, se puede observar que en 1994 se alcanzó el nivel más alto con una participación de $77.20 \%$ decreciendo 20 puntos porcentuales para la elección de 1997 en donde se registró una participación de 57.76\%. De 2000 a 2015 el comportamiento en la participación electoral se muestra estable, en elecciones presidenciales ha oscilado entre el $58.55 \%$ y el 63.97 y en elecciones intermedias entre $41.68 \%$ y $47.71 \%$.

Los datos que arrojó el Informe País también muestran una relación inversa entre el sentido de eficacia política externa (percepción subjetiva de que uno puede influir cuando participa en la política) y la probabilidad de votar. Ello significa que quienes acuden más a votar lo hacen independientemente de que su voto tenga un efecto en los representantes, o sea, el voto no es un instrumento para que se tomen en cuenta sus intereses. Empero, también se desprende la idea que la participación política es acumulativa, pues quienes participan en actividades distintas del voto, también tienden a acudir más a las urnas. Es decir, la participación no electoral no sustituye o inhibe que las y los ciudadanos expresen su preferencia a través del voto, sino la primera refuerza la segunda.

Adicionalmente, se presenta el problema de la brecha entre el sufragio activo y pasivo de las mujeres. Si bien estas tienden a acudir más a las urnas, representan el $42.4 \%$ de las curules del actual Congreso.

El voto es sólo una de las modalidades de participación política que un individuo puede ejercer, y los resultados electorales son un indicador parcial de la actividad política ciudadana en una sociedad. Aunque la participación política no electoral puede realizarse de manera espontánea es el resultado, las más de las veces, de acciones coordinadas entre diversas personas. En esta tercera dimensión se describen los mecanismos de participación política no electoral, tales como reuniones públicas, manifestaciones callejeras, etcétera.

En México, la forma de participación no electoral más frecuente es conversar con otras personas sobre política (39\%) seguido de la asistencia a reuniones con el cabildo municipal o delegacional. En cambio, las y los mexicanos se involucran mucho menos (11\%) en formas de participación más costosas, como son las manifestaciones públicas, los bloqueos y las huelgas. No obstante, de las personas que

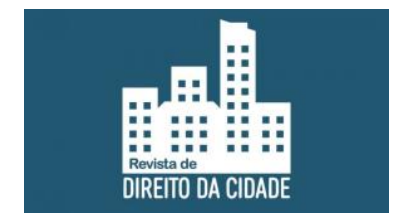

Rev. de Direito da Cidade, Rio de Janeiro, Vol. 14, N.01., 2022, p. 411-429.

Yurisha Andrade Morales

DOI:__ ISSN 2317-7721 
dijeron que habían participado en actividades políticas no electorales el $50 \%$ señaló que éstas no tuvieron el resultado esperado. Por tanto, participar fuera de la política electoral es más costoso y no necesariamente redunda en una mayor eficacia política, lo cual a mediano plazo puede desincentivar este tipo de actividades.

Los costos de la participación no electoral también se reflejan en desigualdades de género y de clase social: los hombres tienden a participar más que las mujeres en actividades no electorales tanto como aquellos que poseen mayor nivel educativo (por lo menos secundaria completa) y recursos. Este dato muestra una de las aristas más preocupantes del problema público de la calidad de la democracia, pues la participación política en actividades no convencionales se traduce en desigualdades políticas para quienes no tienen capacidad de movilización u organización. De esta forma, quienes tienen más recursos son quienes pueden incidir más en la política.

La actividad comunitaria es una dimensión fundamental de la calidad de la democracia, implica un esfuerzo colectivo para resolver problemas comunes y por tanto la existencia previa de cohesión social a partir del involucramiento en organizaciones, redes sociales (fuera de los canales institucionales de las elecciones o los partidos) y en actos de solidaridad y altruismo. En esta dimensión se identifican las modalidades de participación de los ciudadanos en Organizaciones de la Sociedad Civil (OSC), religiosas, culturales, entre otras, así como el apego a normas de reciprocidad y niveles de confianza.

Es particularmente reveladora la debilidad de la vida comunitaria en México pues el $46 \%$ de las y los mexicanos nunca han pertenecido a grupos o asociaciones. Semejante situación excluye a una parte importante de la población de la posibilidad no sólo de resolver problemas comunes sino de acceder a bienes y recursos.

En contraste, quienes mayormente participan en grupos lo hacen a través de asociaciones religiosas (21\%), con particular peso en la región Sureste (29\%) y el Centro-Occidente (28\%). Mientras que sólo el $5 \%$ participan en asociaciones de voluntariado o beneficencia.

Nuevamente, el sexo, los ingresos y el nivel educativo se traducen en desigualdades en este tipo de participación: casi la mitad de las mujeres (49\%) no pertenece a organizaciones y grupos y las personas con menos ingresos y menor nivel educativo son menos propensas a sumarse a este tipo de grupos.

Además de las desigualdades sociales que enfrentan las y los ciudadanos para poder resolver de forma colectiva los problemas de su comunidad, la gran mayoría de las y los mexicanos piensa que los políticos se preocupan nada (50\%) o poco $(22 \%)$ por ellos. Es decir, tres cuartas partes de la población

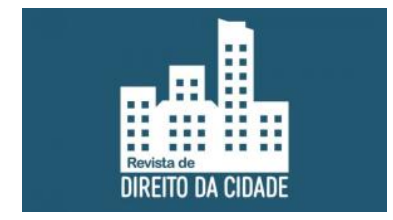

Rev. de Direito da Cidade, Rio de Janeiro, Vol. 14, N.01., 2022, p. 411-429.

Yurisha Andrade Morales

DOI:__ I ISSN 2317-7721 
opinan que los políticos no se preocupan por ellos. Como se subraya en el Informe País, este dato es particularmente grave pues supone un aumento de la desafección política reportada en la ENCUP ${ }^{1}$ de 2008, donde el 44\% reportó que los políticos no se preocupan por gente como ellos. Esta percepción negativa es incluso mayor en el grupo de población con menores ingresos (77\%).

El análisis de los valores es fundamental para poder entender a partir de qué percepciones y creencias actúan los ciudadanos. En esta dimensión se presentan las actitudes que los ciudadanos asumen respecto a la democracia, a la confianza interpersonal e institucional y a la tolerancia; a la aceptación de la pluralidad y al disenso y a la valoración de la legalidad.

Los datos muestran que poco más de la mayoría de la población (53\%) prefiere la democracia a otras formas de gobierno. Sin embargo, $23 \%$ contestó que en algunas circunstancias es preferible un gobierno de mano dura. Incluso, en las regiones Centro y Sureste la preferencia por un régimen autoritario puede llegar a ser superior a la opción de "da lo mismo tener o no un sistema democrático".

Otro dato alarmante es que la mitad de los ciudadanos percibe que la democracia es un sistema "donde muchos participan y pocos ganan", lo cual refleja una visión escéptica respecto de los beneficios de la democracia.

Asimismo, el grado de confianza interpersonal es revelador de los problemas de la calidad de la ciudadanía mexicana, pues el $72 \%$ de las y los mexicanos considera que no se puede confiar en la mayoría de personas, lo cual se acentúa mucho más entre los habitantes de la región Sur y Sureste del país, así como entre personas de menores niveles de educación y salario.

En lo que respecta a la confianza institucional los resultados tampoco son alentadores, pues las y los ciudadanos no confían en la mayoría de las instituciones y organizaciones políticas y sociales. Llama la atención que son los partidos políticos y los diputados las instituciones en las que menor confían los ciudadanos (menos del 20\%).

La ciudadanía no está sólo construida como una cualidad individual, sino que depende de una condición relacional surgida a partir del contacto con los otros (individuos, grupos, asociaciones, comunidad, etcétera). Así, el $65 \%$ de los encuestados dijo no tener contactos para canalizar y hacer efectivas sus demandas. En tanto, los contactos mencionados por los encuestados son preponderadamente hombres, especialmente en la intermediación para acceder a derechos. Por el contrario, la intermediación para hacer algo por la comunidad se cuenta con más contactos mujeres.

1 Encuesta Nacional sobre Cultura Política y Prácticas Ciudadanas.

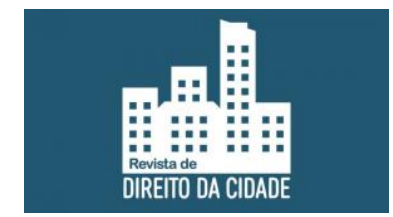

Rev. de Direito da Cidade, Rio de Janeiro, Vol. 14, N.01., 2022, p. 411-429.

Yurisha Andrade Morales

DOI:__ ISSN 2317-7721 
El tipo de relación entre contactos y encuestados es principalmente informal y personal, basada en lazos de amistad, vecindad y familia. La mayoría de los contactos mencionados se encuentran adscritos a alguna dependencia del gobierno. Por tanto, el acceso a espacios formales gubernamentales se hace a partir de relaciones que son profundamente informales y cercanas.

La membresía partidaria y actividades electorales aumentan la probabilidad de estar conectados. En contraste, a menor ingreso mayor desconexión y a medida que aumenta el nivel educativo y de ingresos, aumenta la probabilidad de contar con contactos. En cuanto a la identidad de género, si se es hombre, aumenta la probabilidad de contar con contactos.

El análisis de esta dimensión, centrado en las redes de los encuestados, detectó que una buena parte de mexicanos(as) no detenta capital relacional para el acceso a derechos y la cohesión comunitaria, mientras que entre aquellos que cuentan efectivamente con este tipo de capital, la mayoría posee sólo un contacto, lo que nos habla de escasez y monopolio de la intermediación. Sólo un exclusivo porcentaje posee dos o más contactos lo que permite un mayor grado de libertad y autonomía a la hora de seleccionar caminos de intermediación para acceder a derechos. Ello nos señala un primer nivel de profunda desigualdad en cuanto a capital relacional se refiere. Aunque este contexto resulta desolador vale la pena advertir que lo es aún más para las redes de intermediación que para las de cooperación comunitaria.

En el mismo Informe País se sugieren dos maneras de abordar el problema. La primera consiste en incentivar la participación ciudadana y, la segunda, en fortalecer a las organizaciones de la sociedad civil. Desde esta perspectiva, es necesario desarrollar proyectos orientados a impulsar la toma de decisiones ciudadanas en el ámbito público y a tejer alianzas con dichas organizaciones en el ámbito de la cultura democrática.

\section{ESTRATEGIA NACIONAL DE CULTURA CÍVICA 2017-2023}

Desde 1991 el Instituto Federal Electoral ha implementado estrategias o planes en materia de educación cívica, algunos con vigencia anual y otros multianual, mismos que han evolucionado desde la promoción de los derechos y responsabilidades de los ciudadano hasta identificar las condiciones que limitaban el ejercicio pleno de derechos, con el fin de impulsar acciones colectivas orientadas a mejorarlas.

Es así que en el periodo comprendido de 2011 a 2015 se generaron diversos estudios e investigaciones que hoy nos permiten identificar las condiciones en las que actualmente se ejerce la

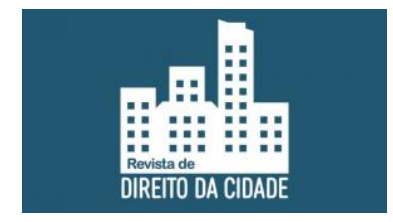

Rev. de Direito da Cidade, Rio de Janeiro, Vol. 14, N.01., 2022, p. 411-429.

Yurisha Andrade Morales

DOI:___ ISSN 2317-7721 
ciudadanía en México, mismos que revelan un complejo panorama por el desencanto de la ciudadanía con los resultados de la democracia y una crisis generalizada de confianza, no sólo hacia las instituciones, sino también en el prójimo, situación que debilita y limita de manera importante la consolidación de la democracia participativa en nuestro país.

Ante este escenario, durante el 2016 el Instituto Nacional Electoral se dio a la tarea de construir la Estrategia Nacional de Cultura Cívica 2017-2023 (ENCCíVICA). Para ello, fue necesario recuperar la experiencia probada del Instituto, así como reconocer la nueva realidad que mandata la legislación electoral en materia de educación cívica. En el proceso de diseño de la ENNCíVICA se identificó la necesidad de atender este tema con un enfoque de política pública, lo cual implicaba: 1) definir el problema público a ser atendido, 2) definir la solución, esto es, la precisión del núcleo duro de la política pública que se estima contribuirá en la solución del problema previamente definido, y 3) el establecimiento de un sistema que permita dar seguimiento y evaluar todos aquellos programas, proyectos y actividades que sean pertinentes y estén alineados al mencionado núcleo.

Un punto nodal para el diseño de la ENCCíVICA fue identificar el grado de aprecio de los mexicanos y mexicanas por la democracia, al respecto, es importante resaltar que 70\% de la población señala no estar de acuerdo con la expresión "los políticos se preocupan por gente como yo", del mismo modo el 71\% de los ciudadanos consideran que no tienen influencia en las decisiones del gobierno y el $50 \%$ declara que la democracia es un sistema donde muchos participan y pocos ganan. Por otra parte, si bien $59.13 \%$ de los encuestados señalan que prefieren la democracia como sistema de gobierno, se advierte una desafección generalizada con el actuar de los políticos. ${ }^{2}$

Ante esta perspectiva, se determinó que la construcción de la ENCCÍVICA debía partir de un diagnóstico exhaustivo acerca de los factores en donde se advierte la debilidad de la cultura democrática, distinguiendo 10 componentes esenciales: la importancia de la información pública; el estado de derecho y los derechos humanos; la gobernanza y la construcción de redes; la perspectiva de género; la interculturalidad; la igualdad y no discriminación; la participación ciudadana más allá de lo electoral; el binomio partidos políticos-gobierno; los medios de comunicación y los espacios del Estado para el fomento de la cultura cívica.

Los datos recabados en cada uno de esos componentes, así como la visión de conjunto que ofrecen, definen los perfiles del problema público al que se quiere hacer frente con la propuesta de

2 Cifras tomadas del Informe País sobre la calidad de la ciudadanía en México.

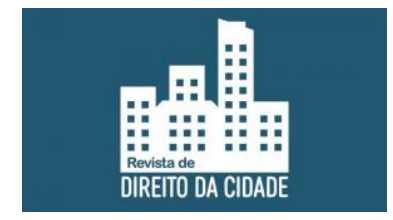

Rev. de Direito da Cidade, Rio de Janeiro, Vol. 14, N.01., 2022, p. 411-429.

Yurisha Andrade Morales

DOI:__ ISSN 2317-7721 
ENCCÍVICA: la debilidad de la cultura democrática de las y los mexicanos. Como ruta para contribuir a la solución de dicho problema, la Estrategia Nacional propone como objetivo superior o fin: crear las condiciones necesarias para que las y los ciudadanos se apropien del espacio público en un sentido amplio y, con ello, contribuir al fortalecimiento de la cultura democrática.

La ENCCÍVICA busca "la apropiación del espacio público por parte de las y los ciudadanos. Sin embargo, se reconoce que su despliegue ocurrirá en un contexto de desigualdad entre las personas, esto es, una sociedad fragmentada ideológicamente y segmentada socialmente, lo que genera no sólo situaciones diferenciadas, sino también límites objetivos a la participación política".

En el planteamiento de la ENCCíVICA se señala expresamente que en la búsqueda del objetivo superior, o fin, la estrategia nacional deberá impulsar la acción colectiva por medio de tres ejes que integran el núcleo duro de la política pública: mucha verdad (información, datos, apertura); mucho diálogo (debates, foros, encuentros); y mucha exigencia (todos los grupos y organizaciones sociales haciendo valer todos sus derechos), subrayando que esas acciones deben realizarse desde abajo, desde adentro y de manera transversal, desde los militantes de los partidos, las organizaciones de la sociedad civil, los sindicatos, la academia, las escuelas, las empresas, los vecinos de los pueblos, las comunidades, las colonias.

La verdad, diálogo y exigencia, constituyen el núcleo duro de la política, y por tanto, el punto de partida para la definición de las ocho líneas de acción que el Comité de Expertos identificó como prioritarias. Las relativas el Eje estratégico de verdad buscan: 1) socializar de la manera más amplia posible los elementos de información necesarios para contribuir a que las y los ciudadanos tengan una idea más precisa y a la vez más completa tanto de su entorno local como nacional y 2) propiciar que la sociedad se escuche a sí misma y, de manera horizontal, comparta la información derivada de su propia experiencia, a fin de utilizarla para su propio beneficio.

Por su parte, las líneas de acción que integran el Eje estratégico de diálogo suponen la formación de grupos de trabajo en los que intervengan actores públicos, privados y sociales. Ello significará realizar reuniones temáticas en las que se privilegie el contacto humano y el desarrollo de diálogos directos y francos entre organizaciones y ciudadanos, grupos académicos, sindicatos, empresas, representantes de los medios, formadores de opinión pública que han defendido agendas públicas específicas, con los representantes de los partidos políticos.

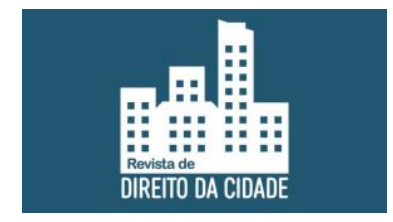

Rev. de Direito da Cidade, Rio de Janeiro, Vol. 14, N.01., 2022, p. 411-429.

Yurisha Andrade Morales

DOI:___ ISSN 2317-7721 
Finalmente, en el Eje estratégico de exigencia busca establecer un mecanismo de monitoreo y seguimiento de las acciones emprendidas por los partidos y los gobiernos -así como de las organizaciones corporativas y ciudadanas- en torno de la coherencia entre lo que postulan y lo que hacen: la congruencia entre sus palabras, sus compromisos y sus actos, más allá del mero cumplimiento de la ley y de las formalidades de procedimiento. Lo anterior, forma parte de las condiciones sin las cuales no será posible reconstruir la confianza en las instituciones políticas del país.

\section{PARTICIPACIÓN CIUDADANA EN MICHOACÁN}

En el artículo 8 de la Constitución Política del Estado de Michoacán se encuentra establecido el derecho de los ciudadanos de votar y ser votados, de participar en las decisiones públicas, la formulación, ejecución y evaluación de las políticas públicas, programas y actos de gobierno a través de los mecanismos de participación ciudadana.

El artículo 29 del Código Electoral del Estado, establece que el Instituto Electoral de Michoacán es un organismo público autónomo, autoridad en la materia, independiente en sus decisiones, con personalidad jurídica y patrimonio propios, responsable de dirigir, organizar y vigilar las elecciones en el Estado, así como de organizar los procesos de participación ciudadana en los términos de las leyes de la materia, y que tales funciones se regirán por los principios de certeza, legalidad, máxima publicidad, equidad, independencia, imparcialidad, objetividad y profesionalismo.

El 8 de septiembre de 2015, se publicó en el Periódico Oficial del Estado de Michoacán de Ocampo, la Ley de Mecanismos de Participación Ciudadana del Estado, misma que reglamenta los mecanismos de participación ciudadana, así como, los procesos para hacerlos efectivos, asegurando mediante la participación y vigilancia ciudadana el completo ejercicio legal y transparente del gobierno.

El 29 de septiembre de 2015, se publicaron en el Periódico Oficial Estado de Michoacán diversas reformas a la Ley de Mecanismos de Participación Ciudadana del Estado de Michoacán de Ocampo, relacionadas con la Consulta Ciudadana a Comunidades Indígenas.

El 27 de abril de 2016 se publicaron en el Periódico Oficial nuevas reformas a la Ley de Mecanismos de Participación Ciudadana del Estado de Michoacán de Ocampo, relacionadas a los Observatorios Ciudadanos, en las que se sustituyó el órgano competente para acreditar dicho mecanismo de participación ciudadana, para serlo ahora el Instituto Electoral de Michoacán.

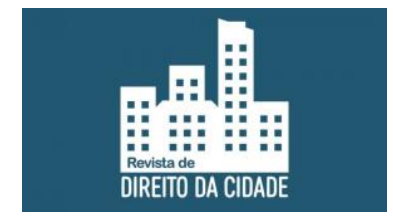

Rev. de Direito da Cidade, Rio de Janeiro, Vol. 14, N.01., 2022, p. 411-429.

Yurisha Andrade Morales

DOI:___ ISSN 2317-7721 
Los mecanismos de participación ciudadana que regula y reconoce esta Ley de Mecanismos de Participación Ciudadana del Estado de Michoacán son:

I. Iniciativa Ciudadana. Es la forma de participación, por la cual, los ciudadanos someten a consideración de los Órganos del Estado, propuestas con el objeto de crear, reformar, adicionar, derogar o abrogar, leyes, decretos o reglamentos.

II. Referéndum. Es el mecanismo de participación mediante el cual los ciudadanos expresan su aprobación o rechazo a leyes o decretos que expida el Congreso; a los decretos, reglamentos, órdenes, acuerdos y circulares de observancia general que contengan disposiciones sobre asuntos administrativos que expida el Gobernador; así como los bandos de gobierno o los reglamentos que emitan los Ayuntamientos.

III. Plebiscito. Es el procedimiento mediante el cual los ciudadanos expresan su aprobación o rechazo a un acto o decisión del Gobernador o de los Ayuntamientos que se considere trascendental para la vida pública y el interés social.

IV. Consulta ciudadana. Es un instrumento de participación mediante el cual los ciudadanos pueden expresar su opinión sobre algún tema de interés público relacionado con el ejercicio de las atribuciones del Poder Ejecutivo y del Poder Legislativo del Estado, así como de los Ayuntamientos.

V. Observatorio Ciudadano. Son órganos plurales y especializados, de participación, coordinación y representación ciudadana, que contribuyen al fortalecimiento de las acciones de los Órganos del Estado en busca del beneficio social. Tienen la finalidad de promover y canalizar la reflexión, el análisis y la construcción de propuestas en torno a los diferentes temas de la vida pública.

VI. Presupuesto participativo. Es el mecanismo por el cual los ciudadanos deciden el destino en que deban aplicarse los recursos públicos considerando proyectos específicos, que versen sobre acciones y obras a realizar en las zonas en que se dividan los municipios.

VII. Consulta Ciudadana a Comunidades Indígenas. La consulta previa, libre e informada es un derecho derivado de la libre determinación de las comunidades y pueblos indígenas, en tanto sujetos de derecho público, atendiendo a los principios de universalidad, interdependencia, indivisibilidad y progresividad. 
La Ley también establece que no podrán ejercitarse mecanismos de participación ciudadana en las siguientes materias:

I. La tributaria o fiscal;

II. Los ingresos o egresos del Estado, salvo la figura de presupuesto participativo; $y$,

III. Las relativas a la regulación interna, funcionamiento e integración de los Órganos del Estado, y la restricción a los derechos fundamentales.

Atendiendo a las atribuciones en materia de participación ciudadana otorgadas al Instituto Electoral de Michoacán, en Sesión Extraordinaria de Consejo General del 9 de diciembre de 2016, se aprobó el Reglamento de Mecanismos de Participación Ciudadana, cuyo objeto es regular los procedimientos de los Mecanismos de participación ciudadana que son competencia del Instituto Electoral de Michoacán, a excepción de la Consulta Ciudadana a Pueblos Indígenas.

Con ello, el Instituto Electoral de Michoacán se encuentra elaborando acciones para que los mecanismos de participación ciudadana señalados en la Ley de la materia del Estado, puedan garantizarse.

\section{REFLEXIONES FINALES}

A manera de conclusión, hago énfasis en la imperante necesidad que se tiene no sólo en México, sino también en la mayoría de los países latinoamericanos, por emprender acciones encaminadas a restructurar la participación política, en principio, buscando mejorar la comunicación e interacción entre la ciudadanía y los políticos. La democracia es un sistema, un mecanismo de organización social, que trae consigo grandes beneficios siempre y cuando los ciudadanos participen de manera activa en la toma de decisiones públicas, sin embargo en una ciudadanía desconfiada que además atraviesa por una seria crisis de representación, se vuelve aún más complejo generar incentivos que eleven los niveles de participación.

Debemos considerar que las desigualdades económicas y sociales tienen un impacto negativo en el ejercicio efectivo de la ciudadanía política y constituyen un obstáculo en la mejora de la calidad de la democracia; por ejemplo, en el Informe País sobre la calidad de la ciudadanía en México se identificó que las personas con menor nivel de ingreso económico tienden a tener un menor aprecio por la democracia, situación que también se observó en personas indígenas y con tez morena, en cambio los segmentos socioeconómicos altos y las personas de tez blanca tienen un mayor aprecio por la democracia. Por tanto

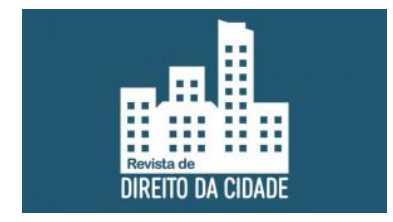

Rev. de Direito da Cidade, Rio de Janeiro, Vol. 14, N.01., 2022, p. 411-429.

Yurisha Andrade Morales

DOI:__ ISSN 2317-7721 
se requiere voluntad política para impulsar acciones contundentes orientadas a disminuir considerablemente las brechas de desigualdad que impiden o limitan la participación de la ciudadanía en mecanismos tanto formales, como informales.

Si bien, tanto en México, como en Latinoamérica, la participación electoral muestra cierta estabilidad a través del tiempo y se muestran niveles positivos de satisfacción con la democracia se observan altos índices de desconfianza no sólo en las instituciones, sino también en el prójimo. Los bajos niveles de confianza entre la ciudadanía y los partidos políticos demandan revisar la vinculación que existe entre ellos y buscar la manera de diversificar los mecanismos de participación. Los bajos niveles de confianza en las instituciones políticas evidencian las dificultades que enfrenta la ciudadanía para optar por formas de participación institucionalizados, es decir pueden preferir otros de tipo más individualista e incluso clientelar.

En México, al igual que en América Latina las cifras revelan que son los jóvenes quienes muestran una menor propensión a votar y una mayor propensión a participar en protestas ciudadanas, por ende se requiere el diseño de políticas públicas orientadas a generar mayor participación de las juventudes. En el caso de México este sector de la población es el que ocupa un gran porcentaje del listado nominal y sería conveniente identificar cuáles son los factores que limitan o frenan su participación, de tal modo que se puedan diseñar políticas encaminadas a incentivar su participación electoral y no electoral.

En México los ciudadanos tienen posibilidades escasas de influir en la actividad del gobierno. Conforme a las cifras arrojadas por el Informe País el porcentaje de individuos que dijeron involucrarse en algún tipo de participación política diferente del voto va de 12\% para la asistencia a una reunión de cabildo, a $2 \%$ en la participación en una huelga. Todas estas cifras se encuentran muy por debajo de las de democracias consolidadas. Es interesante señalar que, con excepción de la edad y el sexo en el caso del voto, las variables sociodemográficas no tienen efecto sobre la probabilidad de involucrarse en otro tipo de acciones políticas. La región Sur es donde los ciudadanos son más contestatarios, pues ahí se firman más peticiones en señal de protesta (58\%) y se participa más en manifestaciones o protestas públicas (68 por ciento).

Una de las razones por las cuales la participación política es limitada en México puede estar asociada con la desconfianza y la desvinculación, de ciudadanos entre sí y entre ciudadanos y gobierno. Por un lado, los ciudadanos mexicanos no se sienten representados, no tienen confianza en los actores clave de la democracia ni en las instituciones teóricamente más cercanas y visibles del Estado: los partidos

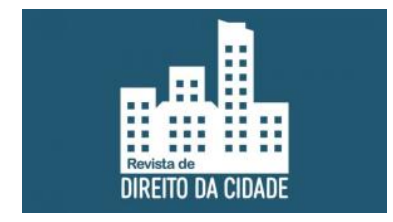

Rev. de Direito da Cidade, Rio de Janeiro, Vol. 14, N.01., 2022, p. 411-429.

Yurisha Andrade Morales

DOI:___ ISSN 2317-7721 
políticos ( $19 \%$ confía mucho y algo), los diputados ( $17 \%$ confía mucho y algo) y la policía ( $32 \%$ confía mucho y algo). Por el otro, la desvinculación de los mexicanos se comprueba por la bajísima pertenencia a asociaciones (46\% de mexicanos reporta nunca haber formado parte de una asociación de ningún tipo) y porque dos tercios de ellos (65\%) no disponen de ninguna relación que constituya un contacto de intermediación para acceder a la justicia, al gobierno, o a recursos políticos o comunitarios. Más aún, 25\% que mencionó tener una sola relación o contacto posee una alta dependencia de él debido a que está atado a una única opción de intermediación o acceso a recursos en una sola área de derechos. Todo esto, aunado a un sentido de eficacia baja (sólo 13\% dijo estar de acuerdo con la frase "Ios políticos se preocupan mucho por lo que piensa la gente como yo", y $12 \%$ con la frase "la gente como yo tiene influencia sobre lo que hace el gobierno"), desalientan la participación y el escepticismo de los ciudadanos sobre la vocación de servicio de los gobernantes.

Como se señala en el estudio complementario al Informe País el cual lleva por nombre "Ciudadanía en México ¿Ciudadanía activa?" (México, 2016) elaborado por el Instituto Nacional Electoral en coordinación con el Colegio de México en cual señala que la idea de Ciudadanía en México no tiene que ver con el ejercicio de un derecho a participar y exigir resultados, sino con cumplir la ley, votar y pagar impuestos. Es decir, ser ciudadano más que un ejercicio activo parece vivirse, en el caso mexicano, como una actividad reactiva y coyuntural. Ser ciudadano no implica, así, una activación e involucramiento en la esfera pública. Más aún, la evidencia indica que para muchos mexicanos la ciudadanía se define en oposición a lo político. Lo político, por su parte, se percibe como lejano, corrupto y que merece poca confianza.

Los mexicanos participan escasamente en actividades políticas, participan mucho más en actividades comunitarias, como la organización de la festividad local o el mejoramiento del espacio común. Por lo tanto, cualquier campaña que tenga como objetivo incrementar la participación política, debe montarse sobre las redes existentes a partir de la participación comunitaria.

\section{FUENTES DE INVESTIGACIÓN}

NOTO, Gerardo (Coord.). Ciudadanía política: voz y participación ciudadana en América Latina. Argentina, 2014. Coed. Programa para el Desarrollo de las Naciones Unidas (PNUD) y Siglo Veintiuno Editores, http://www.juventudconvoz.org/archivos/Estudio-Regional-Ciudadania-Politica-PNUD-2014.pdf

MANN, Michael. The Sources of Social Power. USA, 1986. Volume I. Cambridge University Press.

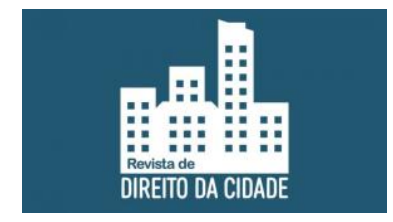

Rev. de Direito da Cidade, Rio de Janeiro, Vol. 14, N.01., 2022, p. 411-429.

Yurisha Andrade Morales

DOI:__ ISSN 2317-7721 
MARSHALL, Thomas Humphrey. "Ciudadanía y clase social”. Centro de Investigaciones Sociológicas. España, 2009. Reis, núm. 79, julio-septiembre.

La democracia en América Latina: hacia una democracia de ciudadanas y ciudadanos. Buenos Aires, 2004. Programa de las Naciones Unidas para el Desarrollo (PNUD). Aguilar, Altea, Taurus, Alfaguara, S. A.

Ciudadanía en México ¿Ciudadanía activa?”. México, 2016, elaborado por el Instituto Nacional Electoral en coordinación con el Colegio de México.

Encuesta Nacional sobre Cultura Política y Prácticas Ciudadanas. Secretaría de Gobernación, http://www.encup.gob.mx/

Estrategia Nacional de Cultura Cívica 2017-2023. México, 2016. Instituto Nacional Electoral, http://www.ine.mx/archivos2/portal/DECEYEC/EducacionCivica/estrategiaNacional/

Estudio Nacional Electoral de México. ENEM 2012. México, 2013. Centro de Investigación y Docencia Económicas (CIDE), http://investigadores.cide.edu/aparicio/data/encuestas/ENE2012/enem\%202012_documento\%20anal\% C3\%ADtico\%20global.pdf

Informe País sobre la calidad de la ciudadanía en México. México, 2015. Instituto Nacional Electoral, El Colegio de México.

Latinobarómetro, la confianza en América Latina 1995 - 2015. 20 años de opinión pública latinoamericana.Chile, 2015, http://www.latinobarometro.org/latNewsShow.jsp

\section{Sobre a autora:}

\section{Yurisha Andrade Morales}

Doctora en Derecho mención Sobresaliente Cum Laude por la Universidad Complutense de Madrid. Doctora en Derecho por el Centro de Investigación y Desarrollo del Estado de Michoacán. Maestra y Licenciada en Derecho por la Universidad Michoacana de San Nicolás de Hidalgo. Coordinadora de la Maestría en Derecho Constitucional en la Universidad Latina de América y catedrática de la misma, así como de la Facultad de Derecho y Ciencias Sociales de la Universidad Michoacana de San Nicolás de Hidalgo.

Universidad Michoacana de San Nicolás de Hidalgo, Morelia, Michoacán, Mexico.

E-mail: yurishaa@hotmail.com

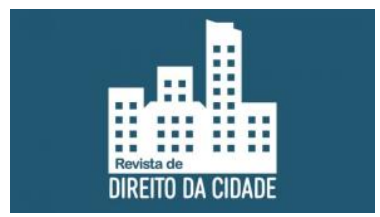

Rev. de Direito da Cidade, Rio de Janeiro, Vol. 14, N.01., 2022, p. 411-429.

Yurisha Andrade Morales

DOI:__ I ISSN 2317-7721 